\title{
Anabases
}

ANABASES Traditions et réceptions de l'Antiquité

22 | 2015

Varia

\section{ReX WINSBURY, Pliny the younger. A life in roman letters}

\section{Cyrielle Landrea}

\section{OpenEdition \\ Journals}

Édition électronique

URL : http://journals.openedition.org/anabases/5528

DOI : 10.4000/anabases.5528

ISSN : 2256-9421

\section{Éditeur}

E.R.A.S.M.E.

\section{Édition imprimée}

Date de publication : 20 octobre 2015

Pagination : 286-288

ISSN : 1774-4296

\section{Référence électronique}

Cyrielle Landrea, "Rex winsbury, Pliny the younger. A life in roman letters », Anabases [En ligne], 22 | 2015, mis en ligne le 20 octobre 2015, consulté le 22 septembre 2020. URL : http://journals.openedition.org/ anabases/5528; DOI : https://doi.org/10.4000/anabases.5528

Ce document a été généré automatiquement le 22 septembre 2020.

(c) Anabases 


\title{
Rex WINSBURY, Pliny the younger. A life in roman letters
}

\author{
Cyrielle Landrea
}

\section{RÉFÉRENCE}

Rex WINSBURY, Pliny the younger. A life in roman letters, Londres, Bloomsbury, 2014, $246 \mathrm{p}$. 21,99 livres / ISBN 9781472514585.

1 Pline le Jeune est un auteur incontournable qui a fait l'objet d'une multitude d'études. Cependant Rex Winsbury ne propose pas une énième relecture des lettres de l'aristocrate et choisit le genre biographique pour réhabiliter Pline le Jeune. En effet, ce dernier a parfois joui d'une mauvaise réputation : celle d'un menteur, d'un homme sans talent littéraire et politique, d'un persécuteur de chrétiens... Loin d'être passé à la postérité comme un exemplum ou un personnage charismatique, Pline a en outre pâti de la comparaison avec Tacite, le grand historien de son temps. R. Winsbury souhaite donc le réhabiliter, en fondant sa recherche sur l'analyse de la correspondance plinienne. Même si Pline a vraisemblablement retravaillé les lettres avant publication, cela ne veut pas dire pour autant qu'elles ont été falsifiées.

2 L'ouvrage s'organise autour de huit grandes thématiques d'une longueur inégale, mais qui embrassent une logique chronologique. La première partie (« Pliny : the case for the prosecution ») est en fait l'introduction. Aux pages 12-13, le lecteur trouvera une rubrique originale ("What this book is not ») où R. Winsbury explique son dessein biographique qui d'ailleurs ne respecte pas un ordre chronologique strict. Le plan se structure plutôt en fonction des aspects de la vie et de la carrière de Pline. Ainsi la deuxième partie («Eye-witnessing Vesuvius ») met-elle en exergue les origines, la jeunesse de l'aristocrate et la fameuse éruption du Vésuve en 79. La troisième partie (« Pliny the rising lawyer ») s'intéresse à la carrière judiciaire qui fut essentielle pour Pline. Trois thèmes sont ici retenus : d'abord ses débuts, puis son opposition au redoutable M. Aquilius Regulus, avant de s'intéresser à la figure du procureur, puisque 
Pline le Jeune a plusieurs fois œuvré contre des gouverneurs accusés notamment de corruption. Contrairement à Cicéron, les discours judiciaires de Pline ont été perdus, ce qui rend sa correspondance une nouvelle fois irremplaçable.

3 La quatrième partie ("In the service of emperors ») aborde le thème du service du prince sous deux angles différents, puisqu'il s'agissait d'abord de survivre sous le principat de Domitien et de gravir les marches du cursus honorum, sans s'attirer les foudres de l'empereur flavien. Puis l'auteur s'attarde sur les manières de plaire à Trajan, l'optimus princeps, et bien évidemment sur le panégyrique controversé prononcé en 100 qui permet d'éclairer l'idéologie impériale. Dans la partie intitulée " Marriages and money ", les mariages et le fait de ne pas avoir eu d'enfant sont étudiés, mais les passages sur le patrimoine de ce sénateur retiennent davantage notre attention. R. Winsbury détermine notamment avec l'historiographie la plus récente la notion de richesse dans le monde romain, tout en s'intéressant aux recettes et aux dépenses de Pline le Jeune.

4 Le patrimoine foncier n'est pas en reste avec l'étude des " posh country villas " qui laisse entrevoir le caractère luxueux des propriétés italiennes de Pline le Jeune. L'appartenance à l'aristocratie romaine ne saurait se limiter aux aspects patrimoniaux et au cursus honorum. Le mécénat et les activités littéraires sont aussi des marqueurs importants. C'est pourquoi la sphère culturelle et intellectuelle est ensuite abordée dans la sixième partie (" Pliny as man of letters »), notamment son cercle littéraire, la question de sa composition et les liens avec de grands auteurs comme Stace ou Juvénal.

5 Dans la septième partie (" Pliny as imperial trouble-shooter »), sa carrière administrative dans la province du Pont-Bithynie est abordée, puisque sa correspondance forme un ensemble inédit qui éclaire le fonctionnement de l'administration impériale. Toutefois plusieurs problèmes sont soulevés, tels la publication des lettres, les relations avec le prince, sans oublier les célèbres passages consacrés aux chrétiens. La dernière partie ("Meeting Pliny ») permet enfin à l'auteur de conclure et de reprendre les principaux points de son analyse.

6 Cet ouvrage a donc toute sa place dans le renouveau des études pliniennes qui est visible depuis quelques années. Il offre aussi une immersion dans une époque culturellement riche où se croisèrent des figures intellectuelles aussi incontournables que Tacite, Suétone ou les poètes Martial et Juvénal. L'un des intérêts de cet ouvrage est de non seulement de s'appuyer sur la correspondance, mais d'en citer de nombreux passages. On peut néanmoins regretter certains choix, comme le fait de ne jamais citer le texte latin des sources antiques (correspondance plinienne incluse), d'avoir réduit à la portion congrue les notes ou parfois de ne pas cacher son admiration pour l'aristocrate. Toutefois le livre de R. Winsbury est plaisant à lire et fait partie des biographies qui permettront de mieux connaître Pline le Jeune. 


\section{AUTEUR}

CYRIELLE LANDREA

Laboratoire ANHIMA

cyrielle.landrea@orange.fr 